\title{
NAS FRONTEIRAS DO PODER. CONFLITO E DIREITO À TERRA NO BRASIL DO SÉCULO XIX
}

Antônio de Pádua BOSI*

\begin{abstract}
MOTTA, M. M. M. Nas fronteiras do poder. Conflito e direito à terra no Brasil do século XIX. Rio de Janeiro: Vício de Leitura/Arquivo Público do Estado do Rio de Janeiro, 1998. 247 p.
\end{abstract}

A visão dos historiadores sobre uma série de questões da História do Brasil, do século XIX, tem mudado muito. Há algum tempo, por exemplo, a história desse período vem sendo apresentada cada vez menos pela ótica da "transição do trabalho escravo para o trabalho livre" ou, ainda, sob a força determinante de "uma economia cafeeira". Em certa medida, trata-se de uma alteração na natureza das perguntas. Alguns dos novos trabalhos têm demonstrado maior interesse em problematizar e discutir como os trabalhadores livres e escravos pensavam e agiam naquele tempo, do que propriamente em produzir explicações globais acerca da sociedade, da economia ou do Estado. Parte desses resultados construídos por essa historiografia podem ser conhecidos e avaliados pela leitura de livros como o recente “Nas Fronteiras do Poder”, de Márcia Motta.

O livro é um exame do direito à terra, no século XIX, visto pela dinâmica dos conflitos ocorridos ao longo das décadas de 1830 à 1850 . A autora identificou 920 pessoas envolvidas em Processos Cíveis de Embargo da Paraíba do Sul/RJ, entre os anos de 1834 e 1858. Por si só, este fato já é relevante, pois contraria afirmações de que "nas fontes do século XIX quase não há referências a conflitos entre grandes e pequenos proprietários"(FRANCO, p. 89). Seu objetivo não foi, contudo, fazer uma

* Professor do Curso de Ciências Sociais da Universidade Estadual do Oeste do Paraná, doutorando em História pelo programa UFF/UNIOESTE e coordenador do Núcleo de Documentação e Pesquisa da UNIOESTE. 
História do Direito Agrário, embora tenha mergulhado no evolver das tentativas de legislação sobre a posse da terra. Márcia Motta propôs-se a identificar e discutir diferentes e, quase sempre contraditórias, percepções a respeito das leis e do direito à terra. Fez disto uma estratégia para reconstruir o desenho e a história da ocupação de terras em Paraíba do Sul. O itinerário, pelo qual ela organizou suas reflexões, procurou respeitar a complexidade dessas percepções e a densa rede social que elas forjaram. Pode-se crer que esse seja o fio condutor adotado pela autora para realizar seu trabalho, bem como a melhor maneira de avaliar o alcance de sua pesquisa.

De forma geral, sustentando toda argumentação no livro, está a noção thompsoniana sobre o domínio da lei (THOMPSON, 1987). Márcia Motta critica a visão que mostra a Lei apenas como "a expressão jurídica da classe dominante" (p. 20). Critica, com efeito, boa parte da historiografia que tomou a Lei de Terras, de 1850, como sendo unicamente o "cativeiro da terra"; a intenção da autora é entendê-la como resultado dos conflitos por terras, onde as pessoas envolvidas buscavam consolidar ou alterar uma determinada situação de posse.

Um exemplo de conflito entre grandes fazendeiros, que tinham assento na Câmara de Deputados, deu-se já por ocasião da confecção da própria Lei de Terras, iniciada em 1843, aprovada em 1850 e regulamentada em 1854. Recompondo a trajetória desses 11 anos de discussão parlamentar sobre a Lei, no capítulo IV, intitulado "Sesmeiros e posseiros nas malhas da Lei" (p. 119-157), a autora esclarece que não houve consenso sobre o que ela deveria legislar. Inicialmente pensada para diferenciar as terras públicas das particulares, esta se revelou contraditória à medida que expressou "percepções diversas sobre os diferentes costumes e concepções em relação ao acesso à terra"'(p. 141). As divergências materializaram-se, por exemplo, nas próprias esferas dos poderes públicos. Atendendo pedido do Presidente da Província do Rio de Janeiro para que se discriminassem as terras públicas das terras privadas, a maioria das Câmaras Municipais informou "a inexistência de terrenos devolutos em seus municípios" (p. 165-167). Esta dimensão do conflito revela o quanto o poder público local podia se apartar do Estado, se os interesses locais dos vereadores estivessem em jogo. É fato, porém, que não há nenhuma novidade em se afirmar que às eventuais discordâncias entre os dominantes podiam corresponder tentativas de instrumentalização do poder público. Entretanto, torna-se um desafio enxergar no Estado, menos sua envergadura monolítica e mais a fragmentação a 
que pode ser reduzido em função da multiplicidade dos interesses daqueles que compartilham dele. Esta reflexão é feita subliminarmente, embora opere ao longo de todo o texto como um convite para se tomar a realidade social referenciada nos muitos conflitos que informam sua dinâmica. Assim, tudo tem uma história que é - ao mesmo tempo - a condição e a expressão dos diversos e, tantas vezes contraditórios, interesses em jogo.

Reconhecer que "a lei tem uma história" (p. 22) levou Márcia Motta a tomar os conflitos de terra como "disputas sobre o sentido da história", ou, o que significa dizer também, disputas sobre determinado sentido da lei. Olhar o campo jurídico dessa forma, como um campo de forças, sugere ver uma lei, em suas brechas e ambigüidades, possível de ser interpretada e, portanto, até certo ponto, maleável. Do contrário, o ingresso de pequenos posseiros na justiça reclamando um direito que acreditavam ter sobre a terra, só poderia ser entendido mesmo como um equívoco, um erro de compreensão da lei. Isto é particularmente discutido no VI capítulo - "O conflito de 1858 revisitado" -, dedicado pela autora aos casos em que pequenos posseiros e agregados descobrem certas dificuldades nas quais os grandes fazendeiros esbarravam quando precisam comprovar a propriedade das terras que alegavam possuir. No acontecimento de maior relevância que ficou marcado por uma sublevação de 86 homens, durante 10 dias, Márcia Motta justapõe a interpretação que os agregados efetuaram sobre a Lei de Terras, de 1850, à interpretação que teve o Barão de Piabanha, argüindo que o fato dos agregados terem sido derrotados no campo da lei não significava que a tivessem entendido erroneamente, mas que, no frigir dos ovos, para explorar as possibilidades da lei, havia prevalecido o ponto de vista de quem conseguira mobilizar maiores esforços, mais dinheiro e poder (p. 207-211).

Ao problematizar a lei dessa forma, a autora evidencia também as relações de dominação presentes em Paraíba do Sul e como elas se davam. Reconceitua as relações de proteção dos fazendeiros com seus agregados como relações tensas, onde o consentimento não era pura e simplesmente uma prerrogativa dos grandes possuidores de terras, mas uma posição constantemente negociada. Havia - mesmo que pequena - uma margem de manobra para o agregado, disponibilizando duas alternativas de sobrevivência: ou "aceitava a condição de agregado do fazendeiro, assegurando o uso de uma parcela das terras, mas reconhecendo o fazendeiro como senhor e possuidor da área ocupada; ou insistia em ser reconhecido como um posseiro, um possuidor de boa fé" (p. 104). Se continuar como agregado signi- 
ficasse o merecimento das graças do fazendeiro, ocupar e requisitar para si um quinhão de terra podia representar "uma possibilidade real de se tornarem lavradores, permitindo alcançarem uma razoável autonomia frente aos interesses dos fazendeiros" (p. 47). A primeira opção implicava, não raras vezes, em auxiliar o fazendeiro nas pendências jurídicas, depondo em seu favor nos Processos de Embargo e avalizando-o contra outros pequenos posseiros. A "proteção" era consentida e lhe permitia a permanência nas terras do fazendeiro. Do contrário, podia reivindicar-se posseiro de trechos fronteiriços não caracterizados ainda nem como terras particulares, nem como devolutas. Para isso, os pequenos posseiros usavam de seu conhecimento sobre as posses do fazendeiro, articulando essas informações numa tentativa de provarem sua própria posse e o uso pioneiro das terras (p. 191194). Eles também tinham seus depoentes, constituídos na maioria dos casos pela parentela ou, ainda, por pequenos e grandes posseiros que tirariam vantagens se as terras do fazendeiro fossem demarcadas e delimitadas (p. 63-85). Este era um jogo complexo que podia mudar de mãos dependendo dos interesses em cena e da correlação de forças estabelecida e montada pelas redes de relacionamento pessoal rivais. Esta característica é fundamental para compor o quadro no qual se constituíam e se moviam as interpretações da lei. Na visão da autora, "os fazendeiros haviam construído uma sociedade na qual o limite das terras estava intimamente ligado à criação e recriação de uma rede de relações pessoais" (p. 214). Quanto mais terras tivessem os fazendeiros, maior seria o número de agregados ligados a elas e, com isso, mais extensa sua rede de relações pessoais que, geralmente, se houvesse necessidade, era acionada como prova nos cartórios locais para forjar suas posses. Nesse contexto, transferir terras significava perder poder sobre pessoas. Do outro lado, os pequenos posseiros também aprenderam a contar com as relações pessoais quando resolviam enfrentar um grande fazendeiro. A complexidade da lei se consumava nesse quadro. Um jogo de peças vivas que, nem sempre, possibilitava predizer o desfecho de um processo.

O livro também tem seus exageros. Talvez o maior deles seja a afirmação da autora de que, em certa medida, a Lei de Terras, de 1850, permitia "uma possibilidade de democratizar o acesso à terra" (p. 142). Os próprios dados discutidos por ela demonstram o contrário, indicando uma substancial concentração de propriedades através da transferência de terras 
devolutas para as mãos dos grandes fazendeiros. No geral, uma minoria de pequenos posseiros conseguiu legalizar suas terras. Todavia, isso não tira a importância e o mérito do livro que é, pode-se dizer, problematizar o domínio da lei como componente da dinâmica dos conflitos sociais. Parte desse exagero, pode ser tomado como resultante de uma postura assumidamente comprometida e, avalio, bem vinda. Sem idealizar o objeto de pesquisa, nota-se que a preocupação da autora é política e norteou tanto a lógica da discussão presente no livro quanto a organização do material empírico que, certamente, foram fundamentais na produção de um conhecimento sobre $o$ Brasil do século XIX, que é crítico e leva à reflexão. Cabe salientar sua importância nesse aspecto, num momento em que a História do Brasil é popularizada por sua vertente positivista lúdica, como é o caso de Os Capitães do Brasil, do jornalista Eduardo Bueno. Ainda, neste sentido, vale lembrar e concordar com Márcia Motta quando afirma que, na atual conjuntura, marcada pela luta de milhares de trabalhadores sem-terra contra as cercas e propriedades constituídas também pela pilhagem dos fazendeiros no século XIX, é difícil não ver nos pequenos posseiros a ousadia e coragem de quererem mudar, de se rebelarem contra a ordem estabelecida e de exigirem direitos sobre a posse da terra. No tempo do Barão de Piabanha, o viajante francês Charles Ribeyrolles se perguntava, a respeito do Brasil, se "uma legislação civil, regulando todos os contratos, uma fórmula simples e rápida, uma jurisprudência clara e bem coordenada, não facilita, em questão de interesse, as soluções e os julgamentos?"(1980, p. 109). Pode-se concluir, após ler o livro, que não. Que a lei não dirime conflitos, mas os recoloca em outros patamares.

Finalizando, na comemoração dos 500 anos, o livro de Márcia Motta investe contra a correnteza da mídia e dos compêndios jornalísticos que tentam aproveitar a data como um evento mercadológico. Originalmente apresentado como tese de doutorado em história, na Unicamp, Nas Fronteiras do Poder chega em boa hora para mostrar a face séria da História contra tantas publicações de curiosidades, feitas segundo a predileção frívola de um mercado livresco acostumado à Caras e Contigo. 